\title{
Aqueous Extract of Inonotus bliquus (Fr.) Pilat (Hymenochaetaceae) Significantly Inhibits the Growth of Sarcoma 180 by Inducing Apoptosis
}

\author{
${ }^{1}$ Caifa Chen, ${ }^{1}$ Weifa Zheng, ${ }^{1}$ Xiaowen Gao, ${ }^{1}$ Xiaoyan Xiang \\ ${ }^{1}$ Dongxu Sun, ${ }^{1}$ Jiangchun Wei and ${ }^{2}$ Chengcai Chu \\ ${ }^{1}$ Key Laboratory for Biotechnology on Medicinal Plants of Jiangsu Province \\ Xuzhou Normal University, Xuzhou 221116, China \\ ${ }^{2}$ National Key Lab of Plant Genomics, Institute of Genetics and Developmental Biology \\ Chinese Academy of Sciences, Beijing 100101China
}

\begin{abstract}
Inonotus obliquus (Fr.) Pilat (Hymenochaetaceae) has been widely used as a folk medicine to treat various cancers in Russia, Poland and most of Baltic countries for literally more than four centuries. However, in spite of its therapeutic significance for cancers, this fungus has not been studied systematically for the mechanisms of antitumor activity. In this study, we report the effects of aqueous extracts of I. obliquus (AEI) on inducing apoptosis of Sarcoma 180. AEI prepared from the sclerotium of I. obliquus was either administered to Sarcoma 180-bearing mice or supplemented into the culture of Sarcoma 180 cells. Oral administration of AEI significantly inhibited Sarcoma 180-induced reduction of splenic lymphocytes and proliferation potentials and elicited over-expression of bax gene in Sarcoma 180 cells, leading to the regression of Sarcoma 180 in mice. Supplementation of AEI into the culture of Sarcoma 180 cells resulted in a significant increase in the number of cells in G0-G1 phase and triggered remarkable increment in programmed death (apoptosis) of Sarcoma 180 cells. In addition, AEI showed stimulatory effect on TNF- $\alpha$ release by mice peritoneal macrophages. These results indicated that the antitumor activity of AEI was mediated by protecting splenic lymphocytes from tumor-induced apoptosis and by triggering apoptosis of tumor cells.
\end{abstract}

Key words: Inonotus obliquus, aqueous extract, apoptosis, antitumor activity

\section{INTRODUCTION}

Inonotus obliquus (Fr.) Pilat (Hymenochaetaceae), a parasitical basidiomycetous fungus usually growing on trunks of living birch, is predominantly distributed in Far East of Russia, Northeast China and other adjacent countries at latitudes of $45^{\circ} \mathrm{N}-50^{\circ} \mathrm{N}$. This fungus has been used to treat various diseases in Russia, Poland and most of Baltic countries for literally more than four centuries. Over the periods I. obliquus has demonstrated peculiar efficacy in treating patients suffering breast cancer, hepatoma, gastrointestinal cancers and other cancers of digestive organs without incurring any unacceptable toxicity ${ }^{[1]}$. It has been reported that the aqueous extracts from I. obliquus (AEI) inhibited HeLa cell proliferation, decreased tumor cell protein content and mitotic index value ${ }^{[2,3]}$ and protected nuclear DNA of human lymphocytes from oxidative damage ${ }^{[4]}$. Mizuno et al. ${ }^{[5]}$ showed that polysaccharides from $I$. obliquus inhibited the growth of various tumor cell lines and $\mathrm{Li}$ et al. ${ }^{[6]}$ found that $30 \%$ ethanol extracts of the fungus suppressed the proliferation of human gastric cancer MGC-803 cells by inhibiting bcl-2 expression.
Be that as it may, the antitumor mechanisms of the fungus have not been well documented, particularly in the respects of systematic assays of its effect on inducing apoptosis of tumor cells ${ }^{[7]}$. In addition, to the best of our knowledge, relatively little is known about its underlying mechanisms against tumor growth in vivo.

It has been generally accepted that tumor microenvironment influences the functional potential of immune cells by secreting immunosuppressive factors to modify the host immune responses ${ }^{[8-11]}$. A number of studies raised the possibilities that tumors of both mouse and human origin can evade immune surveillance by delivering apoptotic death signals to lymphocytes ${ }^{[12]}$. The growth or regression of a tumor inside host body depends on its status of cell proliferation and on apoptosis $^{[13]}$, namely, the progression of a tumor inside host body is determined by the expression of bax and bcl-2 genes ${ }^{[14,15]}$. Bax belongs to the bcl-2 family, the products of which regulate cell death; while the products of bcl-2 are recognized as a survival factor for many types of cells including tumor cells ${ }^{[13]}$. In the present study, we evaluated the effect of AEI on the cell cycle of 
Sarcoma 180 cells, Sarcoma 180-induced reduction of lymphocytes, the expression of bax and bcl-2 genes, and the release of TNF- $-\alpha$ from peritoneal macrophages in tumor-bearing mice in order to better understand antitumor activities of I. obliquus and the underlying mechanisms.

\section{MATERIALS AND METHODS}

RPMI 1640 medium, fetal bovine serum (FBS), were obtained from Hyclone Co.(Logan, UT, USA), Trypan blue, propidium iodide (PI), 3-(4,5-dimethylthiazol-2-yl)-2,5-diphenyl tetrazolium bromide (MTT), sodium thioglycolic acid, RNase A , Dnase I, general reagents 3,3-diaminobenzidine tetrahydrochloride (DAB) and dimethyl sulphoxide (DMSO) were purchased from Sigma Co. (St. Louis, MO, USA). Ficol-hypaque was purchased from Pharmacia Fine Chemicals (Sweden). Mouse tumor necrosis factor- $\alpha$ (TNF- $\alpha$ ) was obtained from Diaclone Inc. (Besancon Cedex, France). Bax and bcl-2 immunohistochemical kits were purchased from Pharmacia (San Jose CA USA); and 96-well plates were purchased from GIBCO BRL (Auckland, New Zealand). Other reagents with high purities were locally purchased.

Preparation of aqueous extract: Inonotus obliquus was collected in Moudanjiang City of Changbai Mountainous region in Northeast China. Voucher specimen (KLBMP005) identified by Prof. Bondartseva, M.A. (Komarov Botanical Institute, Russian Academy of Sciences, St. Petersburg, Russia) was preserved in the Herbarium of Key Laboratory for Biotechnology on Medicinal Plants of Jiangsu Province, China. Well-pulverized sclerotium of I. obliquus $(1 \mathrm{~kg})$ was extracted with boiling water 8 times with one hour each. The extract was filtrated using filter paper (No 5C) followed by concentration in vacuum. The concentrated extract was then lyophilized to afford $109.75 \mathrm{~g}$ black powdered extract (extraction rate, $10.97 \%$ ), which predominately comprised of melanins (56.1\%), polyphenols (19.7\%) and polysaccharides $(22.9 \%)$.

Cell lines: Sarcoma 180 was purchased from Chinese Academy of medical Sciences (Beijing, China). Human kidney cell K293 was kindly provided by Prof. Bao Shilai (Institute of Genetics and Developmental Biology, Chinese Academy of Sciences, Beijing 100101 China). Unless otherwise stated, the cells were grown in RPMI-1640 enriched with $10 \%$ FBS, $50 \mu \mathrm{g} \mathrm{mL} \mathrm{m}^{-1}$ streptomycin and $50 \mu \mathrm{g} \mathrm{mL} L^{-1}$ penicillin in a humidified atmosphere of $5 \% \mathrm{CO}_{2}$ at $37^{\circ} \mathrm{C}$.

Animals: ICR mice were purchased from National Rodent Laboratory Resources, Shanghai, China
(Licensed ID, SCXK2003-0003). The animals were housed at $23 \pm 1^{\circ} \mathrm{C}$, with relative humidity of $55 \pm 10 \%$ and light/dark cycle 12/12 $\mathrm{h}$ and were freely accessible to standard pellet diet and drinking water. The animals were cared humanly according to the Standards for Laboratory Animals of China (GB 14923-94, GB 14922-94 and GB/T 14925-94).

MTT assay: MTT assay was performed according to the procedure previously described ${ }^{[16]}$. Briefly, $20 \mu$ of MTT solution ( $5 \mathrm{mg} \mathrm{mL}^{-1}$ ) was pipetted to the wells of a 96-well plate containing pre-cultured cells and incubated for $4 \mathrm{~h}$ in a humidified atmosphere of $5 \% \mathrm{CO}_{2}$ at $37^{\circ} \mathrm{C}$. At the end of culture period, the supernatant was carefully discarded and the produced formazan crystals were dissolved using $200 \mu \mathrm{L}$ DSO followed by determination of optical density at $570 \mathrm{~nm}$ using an ELISA reader (BioRAD 550, USA).

Tumor model and treatment: ICR mice (male, $\sim 20 \mathrm{~g}$ each; 10 mice in each group) were randomly divided into different groups, including normal set (non-tumor-bearing), AEI-treated normal set $(100 \mathrm{mg}$ $\mathrm{kg}^{-1}$ ), tumor-bearing set (subcutaneously implanted with $1 \times 10^{5}$ exponentially growing Sarcoma 180 cells) and AEI-treated tumor-bearing set (treatment doses were indicated in Table 1). Different doses of AEI were orally administered for 14 consecutive days immediately after Sarcoma 180 transplantation. On day 15, the mice were weighed and sacrificed for the assay of lymphocyte viability and proliferation, index of lymphoid organs, tumor inhibition and expression of bax and bcl-2 genes in Sarcoma 180.

Table 1: Effects of AEI on splenic lymphocyte and proliferative ability

\begin{tabular}{lcc}
\hline Treatment & $\begin{array}{l}\text { Splenic lymphocyte } \\
\text { number }\left(\times 10^{6}\right)\end{array}$ & $\begin{array}{l}\text { Lymphocyte proliferation } \\
\text { (Stimulation Index) }\end{array}$ \\
\hline Normal & $178.21 \pm 14.50$ & $1.04 \pm 0.01$ \\
Normal + AEI & $179.47 \pm 15.36$ & $1.07 \pm 0.02$ \\
$\left(100 \mathrm{mg} \mathrm{kg}{ }^{-1}\right)$ & & \\
$\mathrm{S}_{180}$ & $90.13 \pm 6.55$ & $0.75 \pm 0.02$ \\
$\mathrm{~S}_{180}+\mathrm{AEI}\left(20 \mathrm{mg} \mathrm{kg}^{-1}\right)$ & $165.19 \pm 8.97 *$ & $1.03 \pm 0.04^{*}$ \\
$\mathrm{~S}_{180}+\mathrm{AEI}\left(60 \mathrm{~m} \mathrm{~kg}^{-1}\right)$ & $226.17 \pm 10.37^{* *}$ & $1.44 \pm 0.06^{* *}$ \\
$\mathrm{~S}_{180}+\mathrm{AEI}\left(100 \mathrm{~m} \mathrm{~kg}^{-1}\right)$ & $194.48 \pm 5.19^{*}$ & $1.25 \pm 0.09^{*}$ \\
\hline
\end{tabular}

ICR mice were subcutaneously injected with $1 \times 10^{5}$ Sarcoma 180 cells. After inoculation, AEI was orally administered immediately for 14 consecutive days. At the end of medication, the spleen was sampled aseptically and splenic lymphocytes were isolated for counts and proliferation test. $* P<0.01,{ }^{*} P<0.001$ versus Sarcoma 180 -bearing sets $(n=10)$. Data are expressed as mean \pm S.E. (SSPS).

Isolation of splenic lymphocytes and proliferation assay: Spleens were removed aseptically from the test mice and single cell suspension was made in RPMI 1640 medium. Splenic lymphocytes were purified using Ficol-hypaque as described earlier ${ }^{[17]}$. Viable splenic 
lymphocytes were counted in a haemacytometer by trypan blue exclusion test under a light microscope (400 $\times$, Olympus). For the proliferation assay, the purified lymphocytes $\left(1 \times 10^{5}\right.$ cells well $\left.^{-1} 1\right)$ were resuspended in 10\% FBS enriched RPMI-1640 medium supplemented with $100 \mathrm{U} \mathrm{mL}^{-1}$ penicillin, $100 \mu \mathrm{g} \mathrm{mL}^{-1}$ streptomycin, with or without Con A $\left(5 \mu \mathrm{g} \mathrm{mL}^{-1}\right)$ for a total volume of $200 \mu \mathrm{l}$ and incubated in 96-well-plate in a humidified atmosphere of $5 \% \quad \mathrm{CO}_{2}$ at $37^{\circ} \mathrm{C}$. The lymphocyte proliferation was assayed using the MTT method ${ }^{[18]}$ and expressed as a stimulation index (SI = mean optical values at $570 \mathrm{~nm}$ of stimulated cultures/ mean optical values at $570 \mathrm{~nm}$ of medium control) ${ }^{[19]}$.

Calculation of thymic and splenic index and tumor inhibition: The thymus and spleen were gently removed either from the normal or tumor-bearing mice and weighed immediately. The thymic and splenic index was indicated as weight of thymus or spleen divided by body weight; the inhibitive effect for tumor growth was calculated following the formula: inhibition rate $=\left(\mathrm{W}_{\mathrm{ctr}}\right.$ $\left.-\mathrm{W}_{\text {test }}\right) / \mathrm{W}_{\text {ctr }} \times 100 \%$, where $\mathrm{W}_{\text {ctr }}$ was the tumor weight in AEI-untreated tumor-bearing mice; and $\mathrm{W}_{\text {test }}$ the tumor weight in AEI-treated tumor-bearing mice ${ }^{[20]}$.

Immunohistochemical assay: Immunohistochemical assay was performed by the streptavidin-biotin method. Formalin-fixed, paraffin-embedded tissue sections (4 $\mathrm{mm}$ ) were dewaxed. Endogenous peroxide was blocked with 3\% hydrogen peroxide for $15 \mathrm{~min}$. Bax and bcl-2 was studied by incubation with anti-peptide rabbit antisera specific to these proteins (1:200-400), respectively. All of these antisera have been described previously ${ }^{[21,22]}$ and have been verified to be specific for their intended antigens. Sections were washed and incubated with a biotinylated secondary antibody (Dakopatts, Glostrup, Denmark). The reaction product was visualized by DAB. Nuclei were slightly counterstained with hematoxylin. The particles were counted under light microscope (100 400 × Olympus) with Image-Pro Plus 5.02. The results were indicated as the number of brown expressed particles present in each $\mathrm{mm}^{2}$.

In vitro inhibition assay: The cell lines of Sarcoma 180 and human kidney cell K293 were incubated in 96-well-plate with $1.0 \times 10^{5}$ cells in each using RMPI-1640 medium supplemented with AEI at concentrations of $0,20,60$ and $100 \mu \mathrm{g} \mathrm{mL}^{-1}$ for $4 \mathrm{~h}$. At the end of culture period, the Sarcoma 180 cell suspension was counted for viability with a haemacytometer using trapan blue exclusion test under a light microscope $(400 \times$, Olympus). Growth inhibition of Sarcoma 180 cells was calculated according to the formula: inhibition rate $=\left(1-\mathrm{N}_{\text {test }} / \mathrm{N}_{\text {ctr }}\right) \times 100 \%$, where $\mathrm{N}_{\text {test }}$ was the number of viable Sarcoma 180 cell under interaction of AEI and $\mathrm{N}_{\mathrm{ctr}}$ the number of normally growing Sarcoma 180 cells.

Detection of apoptosis by flowcytometry: Sarcoma 180 cells, either from normally growing culture or from the culture supplemented with AEI, were fixed with p-formaldehyde, permeabilized with Triton $\times 100$ and nuclear DNA was labeled with PI using Cycle TEST PLUS DNA reagent kit. Cell cycle phase distribution of nuclear DNA was determined on fluorescence-activated cell sorter coupled with florescence detector equipped with $488 \mathrm{~nm}$ Argon Laser light source and $623 \mathrm{~nm}$ band pass filter using CellQuest software (Becton Dickinson). Flowcytometric data were analyzed by ModFit software. Histogram display of DNA content ( $x$-axis, PI-fluorescence) versus counts ( $y$-axis, cell number) was displayed.

TNF- $\alpha$ release from peritoneal macrophages: Peritoneal macrophages from six normal mice or Sarcoma 180-bearing mice (male) were induced by intraperitoneal injection with $2 \mathrm{ml} 0.6 \%$ sodium thioglycolic acids 3 days in advance, prepared and cultivated in 24-well-plate as described previously ${ }^{[23]}$. One $\mathrm{ml}$ of RPMI-1640 medium containing AEI at concentrations of $0,20,60$ and $100 \mu \mathrm{g} \mathrm{mL} \mathrm{mas}^{-1}$ wat pipetted to the wells, containing an actively growing monolayer of macrophages and incubated for $4 \mathrm{~h}$. At the end of culture period, the supernatants were removed and the cells were rinsed three times with RPMI-1640 followed by reincubation with RPMI-1640 under the same conditions for another $24 \mathrm{~h}$. The supernatants of the culture were determined for the release of TNF- $\alpha$ using a mouse TNF- $\alpha$ reagent kit.

Statistical analysis: The data obtained in the experiments were processed using SPSS 10.0 software. The assumptions of analysis of variance were considered to be statistically significant at $p<0.05$. The results were expressed as mean \pm S.E.

\section{RESULTS}

Splenic lymphocyte count and proliferation: Lymphocytes play an important role in the immune defense against tumorgenesis. We hereby examined the effect of AEI on splenic lymphocyte number and proliferation potential in normal and Sarcoma 180-bearing mice. Normal mice daily treated with AEI at a dose of $100 \mathrm{mg} \mathrm{kg}^{-1}$ showed no obvious change in splenic lymphocyte number and proliferation capacity when compared to the normal counterparts (Table 1). However, transplantation of Sarcoma 180 cells resulted in a significant reduction of splenic lymphocytes and proliferation potential. In Sarcoma 180 model mice, the number of splenic lymphocytes was nearly halved and 
the proliferation potential was reduced to $3 / 4$ of that in normal mice (Table 1). Oral treatment of Sarcoma 180-bearing mice with AEI at a dose of $20 \mathrm{mg} \mathrm{kg}^{-1}$ dramatically restored splenic lymphocyte number and proliferation potential. At doses of 60 and $100 \mathrm{mg} \mathrm{kg}^{-1}$, these parameters were further enhanced and exceeded the levels of normal mice (Table 1).

Thymic and splenic index: The lymphoid organs are the places where lymphocytes maturation and differentiation take place and therefore are associated with the immune surveillance for tumorgenesis. Oral administration of AEI at a dose of $100 \mathrm{mg} \mathrm{kg}^{-1}$ suggested no obvious change in the index of lymphoid organs in normal mice as compared to the normal untreated counterparts. The transplantation of Sarcoma 180 gave rise to the reduction of the index of lymphoid organs and particularly to the reduction of thymic index. In Sarcoma 180-bearing mice, the thymic index was nearly reduced in half and splenic index reduced to about 2/3 of the normal level. Oral treatment of Sarcoma 180-bearing mice with AEI at 20 and $100 \mathrm{mg} \mathrm{kg}^{-1}$ restored the index of the two lymphoid organs to the normal level. Dose treatment of AEI at $60 \mathrm{mg} \mathrm{kg}^{-1}$ reduced the thymic index from 3.23 to 1.81 , but increased the splenic index from 6.05 to 11.22 (Table 2).

Table 2: $\quad$ Effects of AEI on lymphoid organs, lymphocyte numbers and growth of Sarcoma 180 in tumor- bearing mice

\begin{tabular}{lll}
\hline Treatment & $\begin{array}{l}\text { Thymic index } \\
\left(\mathrm{mg} \mathrm{g}^{-1}\right)\end{array}$ & $\begin{array}{l}\text { Splenic index } \\
\left(\mathrm{mg} \mathrm{g}^{-1}\right)\end{array}$ \\
\hline Normal & $2.37 \pm 0.42$ & $6.01 \pm 1.31$ \\
Normal + AEI $\left(100 \mathrm{mg} \mathrm{kg}^{-1}\right)$ & $2.27 \pm 0.37$ & $5.78 \pm 0.49$ \\
$\mathrm{~S}_{180}$ & $1.26 \pm 0.29$ & $4.13 \pm 0.64$ \\
$\mathrm{~S}_{180}+$ AEI $\left(20 \mathrm{mg} \mathrm{kg}^{-1}\right)$ & $3.30 \pm 0.41^{* *}$ & $6.10 \pm 0.39^{*}$ \\
$\mathrm{~S}_{180}+\mathrm{AEI}\left(60 \mathrm{~m} \mathrm{~kg}^{-1}\right)$ & $1.81 \pm 0.23$ & $11.22 \pm$ \\
$1.59^{* *}$ & & \\
$\mathrm{~S}_{180}+\mathrm{AEI}\left(100 \mathrm{mg} \mathrm{kg}^{-1}\right)$ & $2.19 \pm 0.17^{*}$ & $5.49 \pm 0.29$ \\
\hline
\end{tabular}

ICR mice were subcutaneously injected with $1 \times 10^{5}$ Sarcoma $180\left(\mathrm{~S}_{180}\right)$ cells. After inoculation, AEI was orally administered immediately for 14 consecutive days. At the end of medication, the spleen and thymus were sampled for assaying their indices. Solid type of Sarcoma 180 was isolated and weighed for calculating inhibition rate. ${ }^{*} P<0.01$, ${ }^{* *} P<0.001$ versus Sarcoma 180 -bearing sets $(\mathrm{n}=10)$. Data are expressed as mean \pm S.E. (SSPS)

Expression of bax and bcl-2 genes in Sarcoma 180: To determine whether AEI could interfere with the expression of bax and bcl-2 genes of tumors, the AEI-treated or untreated Sarcoma 180-bearing mice were assayed for the pro- and anti-apoptotic proteins expressed by the two genes using immunohistochemical method. In Sarcoma 180 model mice, the anti-apoptotic bcl-2 gene was over expressed (brown particles); while the expression of the pro-apoptotic bax gene was obviously suppressed in normally growing Sarcoma 180 (Fig. 1) and the weight of Sarcoma 180 reached $2.19 \mathrm{~g}$

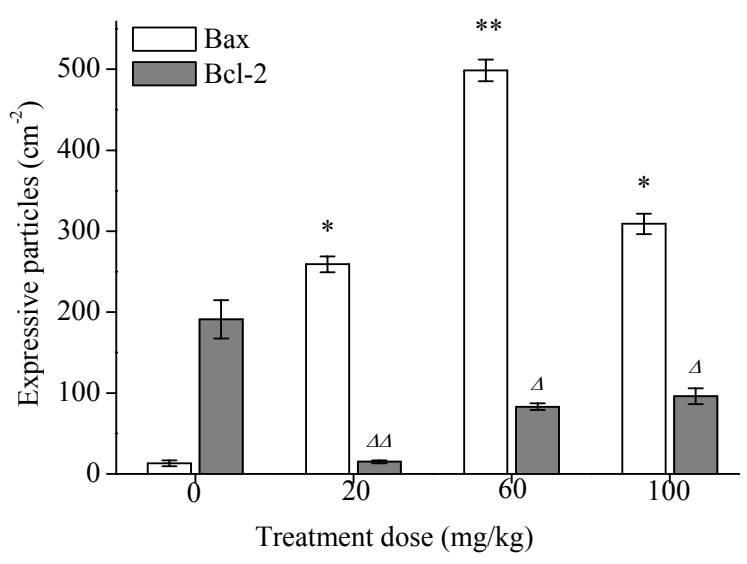

(A)

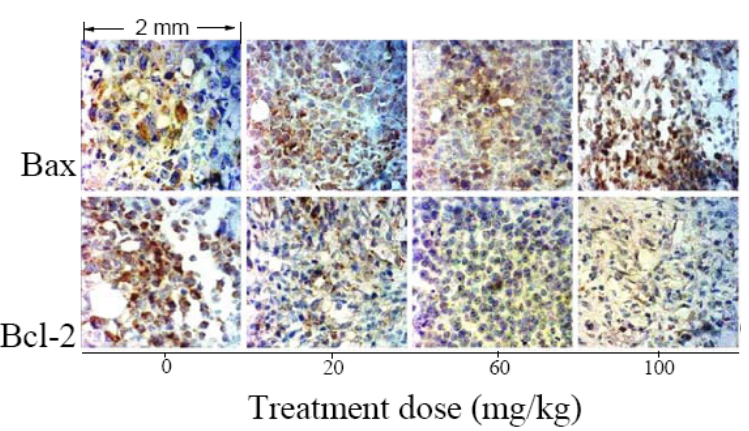

(B)

Fig. 1: Effects of AEI on the expression of bax and bcl-2 genes. ICR mice were subcutaneously injected with $1 \times 10^{5}$ Sarcoma 180 cells. Immediately after inoculation, AEI was orally administered for 14 consecutive days. At the end of medication, the solid tumors of Sarcoma 180 were sampled either from AEI-treated or non-treated tumor-bearing mice and sectioned for the assay of bax and bcl-2 expression products using immunohistochemical methods. (A) Number of expression particles of bax and bcl-2 genes; (B) Microphotography $(400 \times 1$, Olympus $)$ of tumor sections showing the brown particles due to expression of bax and bcl-2 genes. $* P<0.01, * * P<0.001$ versus blank control (treatment dose at $\left.0 \mathrm{mg} \mathrm{kg}^{-1}\right)(\mathrm{n}=10) ;{ }^{\Delta} P<0.05,{ }^{\Delta 4} P<0.01$ versus bank control $(n=10)$. Data are expressed as mean \pm S.E. (SSPS)

14 days after transplantation. Treatment of Sarcoma 180-bearing mice using AEI at a dose of $20 \mathrm{mg} \mathrm{kg}^{-1}$ significantly inhibited the expression of bcl-2 gene and stimulated the expression of bax gene (Fig. 1), which was concomitant with a $27.71 \%$ reduction in tumor weight (Fig. 2). The expression of bax was further enhanced under the treatment of AEI at $60 \mathrm{mg} \mathrm{kg}^{-1}$ where a $76.86 \%$ reduction in Sarcoma 180 weight was recorded (Fig. 1 and 2). In tumor section at this treatment dose, the brown particles of the pro-apoptotic protein (bax) were more densely distributed than those of the anti-apoptotic protein (bcl-2) (Fig. 1B). When the dose treatment was further increased to $100 \mathrm{mg} \mathrm{kg}^{-1}$, however, the stimulation of bax expression and inhibition of tumor growth became less effective (Fig. 1 and 2). 

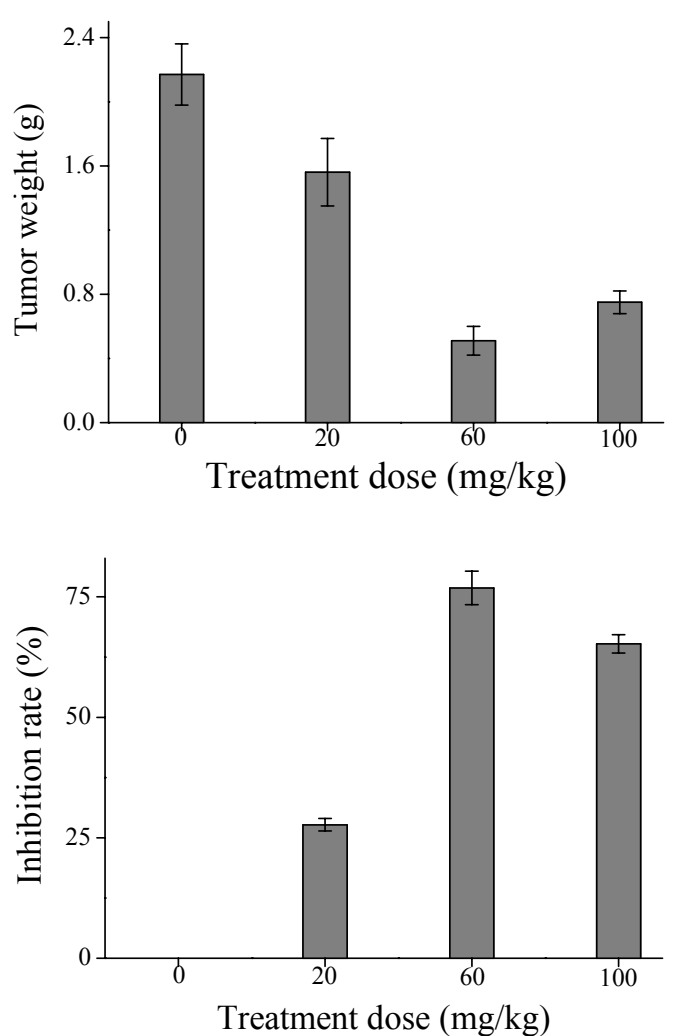

(B)

Fig. 2: Effects of AEI on Sarcoma 180 weight and inhibition. ICR mice were subcutaneously injected with $1 \times 10^{5}$ Sarcoma 180 cells. Immediately after inoculation, AEI was orally administered for 14 consecutive days. At the end of medication, Sarcoma 180 was sampled either from AEI-treated or non-treated tumor-bearing mice and sectioned for the assay of tumor weight and inhibition

In vitro inhibition on Sarcoma 180 cell growth: To determine the cytotoxicity of AEI, K293 and Sarcoma 180 cell lines were co-incubated, respectively, with serially diluted concentrations of AEI. AEI showed a $30 \%$ inhibition in Sarcoma 180 cell proliferation at 20 $\mu \mathrm{g} \mathrm{mL} \mathrm{L}^{-1}$ and suppressed the growth more than $40 \%$ and $57 \%$ at concentrations of 60 and $100 \mu \mathrm{g} \mathrm{mL}^{-1}$, respectively. In contrast, the proliferation of K293 was not significantly affected by AEI at concentrations tested (Fig. 3).

Apoptosis of Sarcoma 180 cells: To characterize the inhibition of Sarcoma 180 cell proliferation, the cell cycle of AEI-treated Sarcoma 180 cells was examined by flow-cytometry as shown in Fig. 3. In normally growing Sarcoma 180 cells, more than $60 \%$ of Sarcoma 180 cells were in $\mathrm{G} 2-\mathrm{M}, 35 \%$ in S and only $2.02 \%$ in G0-G1 phase (Fig. 3A). In agreement with its actively growing status, only $2.06 \%$ cells were undergoing the programmed cell death (apoptosis) (Fig. 3A). In comparison, in Sarcoma 180 cells co-cultured with AEI at a concentration of $20 \mu \mathrm{g} \mathrm{mL}^{-1}$, the cell number in

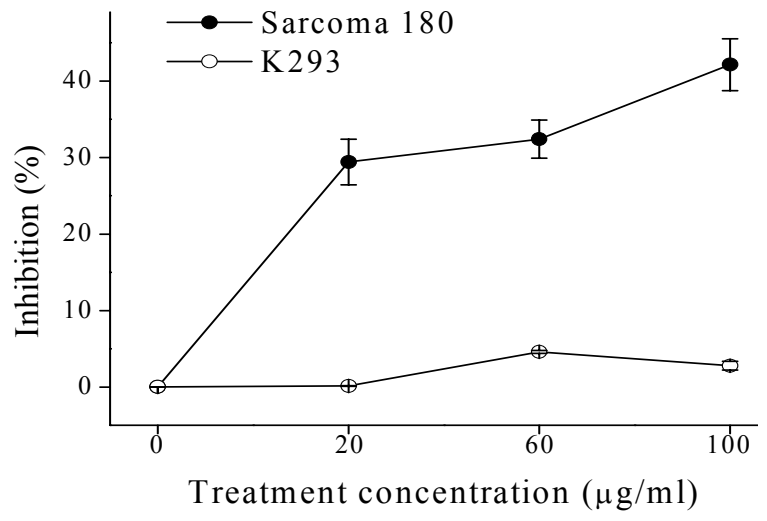

Fig. 3: Inhibitory effect of AEI on growth of Sarcoma 180 cells and mouse fibroblast in vitro. AEI was supplemented aseptically into the culture of Sarcoma 180 and K293 at concentrations of $0,20,60$ and $100 \mu \mathrm{g} \mathrm{mL} \mathrm{m}^{-1}$ and incubated at $37^{\circ} \mathrm{C}$ for $48 \mathrm{~h}$. The inhibition on growth of Sarcoma 180 cells was determined by the MTT assay

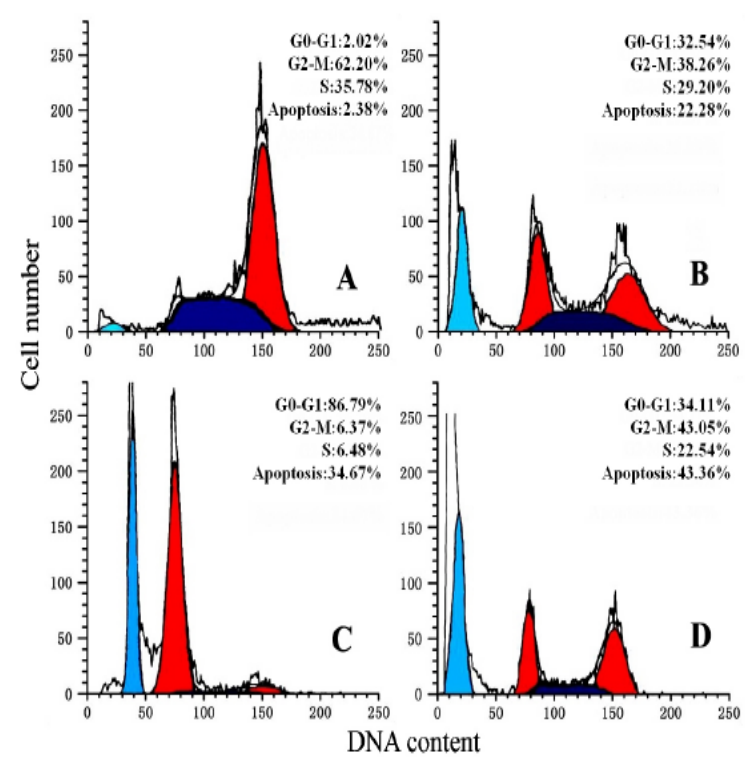

Fig. 4: Flowcytometric analysis of Sarcoma 180 cell cycle phase distribution. Sarcoma 180 cells were treated with or without AEI, fixed and nuclear DNA was labeled with PI. Cell cycle phase distribution of Sarcoma 180 cell nuclear DNA was determined by single label flow-cytometry. Histogram display of DNA content (x-axis, PI-fluorescence) versus cell number (y-axis) has been shown. (A) Normally growing Sarcoma 180 cells, (B) Sarcoma 180 cells of AEI-treated at a concentration of $20 \mu \mathrm{g} \mathrm{mL} \mathrm{m}^{-1}$, (C) Sarcoma 180 cells of AEI-treated at a concentration of $60 \mu \mathrm{g} \mathrm{mL} \mathrm{m}^{-1}$, (D) Sarcoma 180 cells of AEI-treated at a concentration of $100 \mu \mathrm{g} \mathrm{mL}^{-1}$

G0-G1 phase was greatly increased and that in G2-M and $\mathrm{S}$ phase was reduced. At higher AEI concentration, the cell number in G0-G1 phase was further increased with the concomitance of a significant increase in apoptotic Sarcoma 180 cells (Fig. 4). 


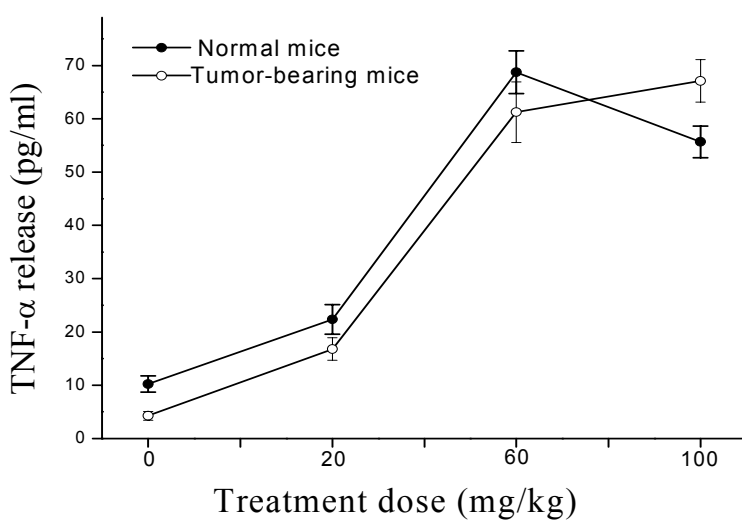

Fig. 5: Stimulatory effects of AEI on TNF- $\alpha$ release from peritoneal macrophages. AEI was supplemented into the culture of monolayer macrophages at concentrations of $0,20,60$ and $100 \mu \mathrm{g} \mathrm{mL}{ }^{-1}$ and cultivated at $37^{\circ} \mathrm{C}$ for $4 \mathrm{~h}$. The medium was removed and the wells were rinsed with RPMI-1640 medium, followed by culturing under the same condition for another 24 h. TNF- $\alpha$ was assayed using a mouse TNF- $\alpha$ reagent kit

TNF- $\alpha$ release from macrophages: To elucidate the possible underlying mechanisms of AEI-induced Sarcoma 180 cell apoptosis, the effect of AEI on TNF- $\alpha$ release by peritoneal macrophages from normal and tumor-bearing mice was also bioassayed. Normally, TNF- $\alpha$ release by peritoneal macrophages from normal mice reached to ca. $10 \mathrm{pg} \mathrm{mL}^{-1}$ in culture filtrates and increased to $22.35 \mathrm{pg} \mathrm{mL}^{-1}$ and $68.73 \mathrm{pg} \mathrm{mL}^{-1}$ following the supplementation of AEI at concentrations of 20 and $60 \mu \mathrm{g} \mathrm{mL}^{-1}$, respectively. Further increase of AEI to 100 $\mu \mathrm{g} \mathrm{mL}^{-1}$, nevertheless, reduced the release of TNF- $\alpha$ in culture filtrate to $55.69 \mathrm{pg} \mathrm{mL}^{-1}$ (Fig. 5). In contrast, the release of TNF- $\alpha$ only reached $4.27 \mathrm{pg} \mathrm{mL}^{-1}$ by peritoneal macrophages from Sarcoma 180-bearing mice in culture filtrate, significantly lower than that of the macrophages from normal mice. Following the supplementation of AEI, however, the release of TNF- $\alpha$ was greatly enhanced and indicated in a dose-dependent manner (Fig. 5).

\section{DISCUSSION}

The number of lymphocytes undergoes massive depletion following tumor transplantation and growth inside the host organism ${ }^{[24,25]}$. In Sarcoma 180-bearing mice model, evident reduction in splenic lymphocytes was observed, reinforcing the notion that tumor development inside the host resulted in the impairment of normal lymphocytes and the reduction of proliferative potential, which was in accordance with those previously reported ${ }^{[26,15]}$. The search for underlying mechanisms revealed apoptosis as the cause of tumor-induced immune cell death in spleen ${ }^{[27]}$. In this study, treatment with AEI at $100 \mathrm{mg} \mathrm{kg}^{-1}$ resulted in no significant reduction in splenic lymphocytes, implying that oral administration of AEI at this dose exerted no immunotoxicity to the test mice. It was also found that lymphocyte proliferation potential was greatly reduced in Sarcoma 180-bearing mice. Oral administration at 60 $\mathrm{mg} \mathrm{kg}{ }^{-1}$ not only protected the lymphoid organ in Sarcoma 180-bearing mice by multiplying the number of splenic lymphocytes, but also stimulated lymphocyte proliferation. It was noted that oral administration of AEI at a dose of $100 \mathrm{mg} \mathrm{kg}{ }^{-1}$ resulted in a slight down-regulation on enhancement of lymphocyte number, proliferation and antitumor effect as compared to that at $60 \mathrm{mg} \mathrm{kg}^{-1}$. Such down-regulations in tumor-bearing mice are likely due to the immunomodulatory effect of polysaccharides present in AEI that higher dose of polysaccharides usually attenuates over-activation of host immune system ${ }^{[20]}$. The growth or regression of a tumor inside the host body largely depends on the expression of bax and bcl-2 genes ${ }^{[14,15]}$. Many anticancer drugs exert their lethality by inducing apoptosis of tumor cells both in vitro and in vivo via mitochondrial or death receptor pathway ${ }^{[28,29]}$. The onset of apoptosis in response to chemotherapy involves the induction or activation of various mediators including expression or function of members of the bcl-2 family ${ }^{[30]}$. Mass production of pro-apoptotic proteins by over-expression of bax resulted in tumor regression. On the contrary, mass expression of bcl-2 creates favorable microenvironment for tumor growth $^{[31]}$. Our results revealed that oral administration of AEI significantly stimulated bax expression and inhibited bcl-2 expression in Sarcoma 180 and consequently exerted evident inhibition on growth of Sarcoma 180. Therefore, the inhibitory effect of AEI on Sarcoma 180 growth is possibly mediated via suppressing bcl-2 expression and stimulating bax expression.

In apoptotic cells, the DNA synthesis was blocked in the G0-G1 phas $\mathrm{e}^{[32]}$. Consequently, the intervention of DNA synthesis of tumor cells becomes one of the therapeutic targets of antitumor drugs. Current therapies of tumors usually employ DNA-damaging agents such as ionizing radiation and chemotherapeutic drugs in addition to surgical removal. However, the application of these agents also gives rise to severe reduction of host lymphocytes when inducing apoptosis of tumor cells ${ }^{[33]}$. The side effects of chemotherapies greatly limit treatment dose and prognosis. Burczyk et al. ${ }^{[2]}$ showed that AEI blocked mitosis of HeLa cells by elevating the number of mitotic cells in G0-G1 phase in vitro. In this study, AEI also showed direct tumorcidal effect against Sarcoma 180 cells by increasing cell number in G0-G1 phase whereby induced programmed cell death. On the other hand, AEI also showed protective effect against oxidative DNA-damage in human lymphocytes ${ }^{[4]}$. In this study, AEI effectively protected splenic lymphocytes from Sarcoma 180-induced reduction in 
tumor-bearing mice. These results clearly indicated that AEI selectively induced apoptosis of tumor cells.

TNF is one of the factors released by activated macrophages, NK-cells and T-lymphocytes ${ }^{[34]}$. Adequate dose of TNF can induce death receptor-mediated programmed cell death (apoptosis) ${ }^{[35]}$. Our results showed that supplementation of AEI into the culture of peritoneal macrophages resulted in a significant increase in TNF- $\alpha$ release. Therefore, one of the mechanisms for triggering tumor apoptosis by AEI is likely to be the activation of macrophages and possibly other lymphocytes, leading to an enhanced TNF release.

\section{CONCLUSION}

These findings evidenced the effective protection of AEI against tumor-induced apoptosis of lymphocytes and significant potential for inducing apoptosis of tumor cells. It could also establish the involvement of enhanced release of TNF and death regulatory proteins, as well as their interactions in immune system in response to tumorgenesis. Since the therapeutic application of I. obliquus has lasted for literally more than four centuries, the elucidation of its mechanisms of antitumor activity reconfirmed this mysterious fungus as an immune restoring and successful antitumor agent with high selectivity and safety.

\section{ACKNOWLEDGEMENTS}

This work was financially supported by a grant of key project from natural science foundations of education department of Jiangsu province (Grant No. 05KJA36012), and a grant of Natural Science foundation of Jiangsu Province (grant No BK2006034)

\section{REFERENCES}

1. Huang, L.N., 2002. The mysterious folk medicinal fungus-Inonotus obliquus. Edible Fungi Chin., 21: 7-8.

2. Burczyk, J., A. Gawron, M. Slotwinska, B. Smietana and K. Terminska, 1996. Antimitotic activity of aqueous extracts of Inonotus obliquus. Boll. Chim. Pharm., 135: 306-9.

3. Rzymowska, J., 1998. The effect of aqueous extracts from Inonotus obliquus on the mitotic index and enzyme activities. Boll. Chim. Pharm., 137: 13-5.

4. Park, Y.K., H.B. Lee, E.J. Jeon, H.S. Jung and M.H. Kang, 2004. Chaga mushroom extract inhibits oxidative DNA damage in human lymphocytes as assessed by comet assy. BioFactors, 21: 109-12.

5. Mizuno, T., C. Zhuang, K. Abe, H. Okamoto, T. Kiho, S. Ukai, S. Leclerc and L. Meijer, 1999. Antitumor and hypoglycemic activities of polysaccharides from the sclerotia and mycelia of Inonotus obliquus. Intl. J. Med. Mush., 1: 301-16.
6. Li, Y.X., J.C. Cui, D.Z. Sun, Y.Z. Gao and Y. Cui, 2003. Effect of extractions from edible fungus Inonotus obliquus (Fr.) Pilat on anti-proliferation and apoptosis inducement of MGC-803 cells of gastric cancer. J. Fun. Res., 1: 17-23.

7. Cui, Y., D.S. Kim and K.C. Park, 1997. Antioxidant effect of Inonotus obliquus. J. Ethnopharmcol., 96: 79-85.

8. Chouaib, S., C. Asselin-Paturel, F. Mai-Chouaib, A. Caignard and J.Y. Blay, 1997. The host-tumor immune conflict: From immunosuppression to resistance and destruction. Immunol. Today, 18: 493-7.

9. Pawelec, G., J. Zeuthen and R. Kiessling, 1997. Escape from host-antitumor immunity. Crit. Rev. Oncol., 8: 111-41.

10. Shu, S., G.E. Plautz, J.C. Krauss and A.E. Chang, 1997. Tumor immunology. J. Am. Med. Assoc., 278: 1972-81.

11. Chen, L., 1998. Immunological ignorance of silent antigens as an explanation of tumor evasion. Immunol. Today, 19: 27-30.

12. Seliger, B., 2005. Strategies of tumor immune evasion. BioDrugs, 19: 347-54.

13. Kymionis, G.D., C.E. Dimitrakakis, M.M. Konstadoulakis, I. Arzimanoglou, E. Leandros, G. Chalkiadais, A. Keramopoulos and S. Michala, 2001. Can expression of apoptosis genes, $b c l-2$ and bax, predict survival and responsiveness to chemotherapy in node-negative breast cancer patients? J. Surg. Res., 99: 161-8.

14. Pratesi, G., D. Polizzi, P. Perego, L. Dal Bo and F. Zunino, 2000. Bcl-2 phosphorylation in a human breast carcinoma xenograft: a common event in response to effective DNA-damaging drugs. Biochem. Pharmacol., 60: 77-82.

15. Bhattacharyya, A., D. Mandal, L. Lahiry, G. Sa and T. Das, 2004. Black tea protects immunocytes from tumor-induced apoptosis by changing Bcl-2/Bax ratio. Cancer Lett., 209: 147-54.

16. Page, M., N. Bejaoui, B. Cinq-Mars and P. Lemieux, 1988. Optimization of the terazolium-based colorimetric assay for the measurement of cell number and cytotoxicity. Int. J. Immunopharmacol., 10: 785-93.

17. Tomai, M.A., L.M. Imbertson, T.L. Stanczak, L.T. Tygrett and T.J. Waldschmidt, 2000. The immune response modifiers imiquimod and R-848 are potent activators of $\mathrm{B}$ lymphocytes. Cellular Immunol., 203: 55-65.

18. Gieni, R.S., Y. Li and K.T. Hayglass, 1995. Comarison of $\left[{ }^{3} \mathrm{H}\right]$ thymedine incorporation with MTT- and MTS-based bioassys for human and murine IL-2 and IL-14 analysis Tetrazolium assays provide markedly enhanced sensitivity. J. Immunol. Methods, 187: 85-93.

19. Orlik, O. and G.A. Splitter, 1996. Optimization of lymphocyte proliferation assay for cells with high spontaneous proliferation in vitro: $\mathrm{CD}^{+} \mathrm{T}$ cell proliferation in bovine leukemia virus infected animals with persistent lymphocytosis. J. Immunol. Methods, 199: 159-65. 
20. Zheng, W.F., C.F. Chen and Q.P. Cheng, 2005. Antitumor activity of exopolysaccharide from Aphanothece halophytica. Chin Tradit Herbal Drugs, 36: 1026-30.

21. Krajewski, S., M. Krajewska, A. Shabaik, H.G. Wang, S. Irie, L. Fong and J.C. Reed, 1994. Immunohistochemical analysis of in vivo patterns of Bcl-X expression. Cancer Res., 54: 5501-7.

22. Krajewski, S., C. Blomvqvist, K. Franssila, M. Krajewska, V.M. Wasenius, E. Niskanen, S. Nordling and J.C. Reed, 1995. Reduced expression of pro-apoptotic gene Bax is associated with poor response rates to combination chemotherapy and shorter survival in women with metastic breast adenocarcinoma. Cancer Res., 55: 4471-8.

23. Kim, H.M., C.H. Oh and C.K. Chung, 1999. Activation of inducible nitric oxide synthase by Taraxacum officinale in mouse peritoneal macrophages. Gen. Pharmacol., 32: 683-8.

24. Ghosh, M., U. Sadhu, S.D. Bhattacharya, B. Bhattacharya and U. Sanyal, 1999. Evaluation of toxicity of betatethymustine, A new anticancer compound in mice. Cancer Lett., 138: 107-14.

25. Shanker, A., S.M. Singh and A. Sodhi, 2000. Ascitic growth of a spontaneous transplantable $\mathrm{T}$ cell lymphoma induces thymic involution. 2 . Induction of apoptosis in thymocytes. Tumor Bio., 21: 315-27.

26. Bhattacharyya, A., T. Choudhuri, S. Pal, S. Chattopadhyay, G.K. Datta, G. Sa and T. Das, 2003. Apoptogenic effects of black tea on Ehrlich's ascites carcinoma cell. Carcinogenesis, 24: 75-80.

27. Nagarkatti, N., 2000. Turmor-derived Fas ligand induces toxicity in lymphoid organs and play an important role in successful chemotherapy. Cancer Immunol. Immun., 49: 46-55.
28. Kaufmann, S.H. and W.C. Earnshaw, 2000. Induction of apoptosis by cancer chemotherapy. Exp. Cell Res., 256: 42-9.

29. Johnstone, R.W., A.A. Ruefli and S.W. Lowe, 2002. Apoptosis: a link between cancer genetics and chemotherapy. Cell, 108: 153-64.

30. Brantley-Finley, C., C.S. Lyle, L. Du, M.E. Goodwin, T. Hall, D. Szwedo, G.P. Kaushal and T.C. Chambers, 2003. The JNK, ERK and p53 pathways play distinct roles in apoptosis mediated by the antitumor agents vinblastine, doxorubicin and etoposide. Biochem. Pharmacol., 66: 459-69.

31. Zheng, J.Y., G.S. Yang, W.Z. Wang, J. Li, K.Z. Li, W.X. Guan and W.L. Wang, 2005. Over expression of Bax induces apoptosis and enhances drug sensitivity of hepatocellular cancer-9204 cells. World J. Gastroenterol., 11: 3498-503.

32. Suffness, M., and J.M. Pezzuto, 1991. Methods in Plant Biochemistry. Academic Press, New York, Vol. V1, pp: 7.

33. Ishiki, N., H. Onishi and Y. Machida, 2004. Evaluation of antitumor and toxic side effects of mitomycin C-estradiol conjugates. Intl. J. Pharma., 279: 81-93.

34. Mocellin, S., C.R. Rossi, P. Pilati and D. Nitti, 2005. Tumor necrosis factor, cancer and anticancer therapy. Cytokine Growth Factor, 16: 35-53.

35. Leist, M. and M. Jaattela, 2001. Four deaths and a funeral: from caspases to alternative mechanisms. Nat. Rev. Mol. Cell Bio., 2: 589-98. 